\title{
Chrysophanol inhibits proliferation and induces apoptosis

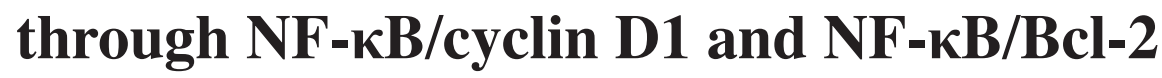 signaling cascade in breast cancer cell lines
}

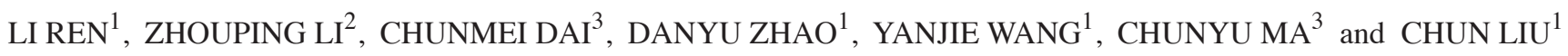 \\ ${ }^{1}$ Department of Biochemistry and Molecular Biology, Liaoning University of Traditional Chinese Medicine, Shenyang, \\ Liaoning 110032; ${ }^{2}$ Department of Aesthetic and Plastic Surgery, First Affiliated Hospital of Jinzhou Medical University, \\ Jinzhou, Liaoning 121004; ${ }^{3}$ College of Pharmacy, Jinzhou Medical University, Jinzhou, Liaoning 121000, P.R. China
}

Received February 5, 2017; Accepted August 3, 2017

DOI: $10.3892 / \mathrm{mmr} .2018 .8443$

\begin{abstract}
Chrysophanol is an anthraquinone compound, which exhibits anticancer effects on certain types of cancer cells. However, the effects of chrysophanol on human breast cancer remain to be elucidated. The aim of the present study was to clarify the role of chrysophanol on breast cancer cell lines MCF-7 and MDA-MB-231, and to identify the signal transduction pathways regulated by chrysophanol. MTT assay and flow cytometric analysis demonstrated that chrysophanol inhibited cell proliferation, and cell cycle progression in a dose-dependent manner. The expression of cell cycle-associated cyclin D1 and cyclin E were downregulated while p27 expression was upregulated following chrysophanol treatment at the mRNA, and protein levels. The Annexin V/propidium iodide staining assay results revealed that apoptosis levels increased following chrysophanol treatment. Chrysophanol upregulated caspase 3 and poly (ADP-ribose) polymerase cleavage in both cell lines. Furthermore, chrysophanol enhanced the effect of paclitaxel on breast cancer cell apoptosis. In addition, chrysophanol downregulated apoptosis regulator Bcl-2 protein, and transcription factor p65 and IкB phosphorylation. Inhbition of nuclear factor (NF)- $\mathrm{kB}$ by ammonium pyrrolidine dithiocarbamate diminished the effect of chrysophanol on apoptosis and associated proteins. In conclusion, the results of the current study demonstrated that chrysophanol effectively suppresses breast cancer cell proliferation and facilitates chemosentivity through modulation of the NF- $\mathrm{KB}$ signaling pathway.
\end{abstract}

Correspondence to: Dr Chun Liu, Department of Biochemistry and Molecular Biology, Liaoning University of Traditional Chinese Medicine, 79 Chongshan Eastern Road, Shenyang, Liaoning 110032, P.R. China

E-mail: uogeci@163.com

Key words: chrysophanol, breast cancer, proliferation, cell cycle, apoptosis

\section{Introduction}

Breast cancer remains the most common cancer in women worldwide and its mortality rate is increasing. This disease may cause serious harm to physical and mental health of women. Surgery remains the primary treatment in most cases and entails the complete removal of the primary tumour in the breast $(1,2)$. Traditional Chinese herbal medicine (CHM), as an adjunctive treatment following surgery, radiotherapy and chemotherapy, may prolong survival time and improve the quality of life of breast cancer patients.

Chrysophanol (1,8-Dihydroxy-3-methyl-9,10anthraquinone) belongs to anthraquinone family, which also contains emodin, aloe-emodin, rhein, and physcion.

Derivatives of anthraquinone family are natural products, which were mainly extracted from rhubarb and used in CHM (3-5). As a palliative treatment, CHM was commonly used with oral administration for different types of cancers in China (6-8).

There were some reports indicating that rhubarb extracts induced apoptosis or inhibit migration of cancer cells $(9,10)$. For example, emodin extracted from rhubarb root has anti-cancer effects in numerous cancers such as prostate, breast and cervical cancers (11-15). Chrysophanol was also reported for its anti-cancer role, showing that it inhibits viability of colon cancer cells through inhibition of the NF- $\mathrm{KB}$-mediated signaling cascades (16). In choriocarcinoma, Chrysophanol induced cell apoptosis by regulating production of reactive oxygen species (ROS) through AKT and ERK1/2 signaling pathways (17). Chrysophanol induces necrosis in A549 cells through increasing ROS and decreasing the level of mitochondrial membrane potential (3). Chrysophanol also impairs mitochondrial ATP synthesis in Hep3B cells (4). However, whether chrysophanol play a role in breast cancer development is still unknown. This study aims to find out the biological effects of chrysophanol on breast cancer and the potential mechanism.

\section{Materials and methods}

Chemicals. Chrysophanol (cat no. 01542) and Paclitaxel (cat no. 1491332) were purchased from Sigma-Aldrich 
(St. Louis, MO, USA). NF- $\kappa B$ inhibitor (BAY 11-7082; cat no. S1523) was purchased from Beyotime Institute of Biotechnology (Shanghai, China).

Cell culture. Breast cancer cell line MCF-7 and MDA-MB-231 were purchased from the American Type Culture Collection (Manassas, VA, USA) and cultured in RPMI-1640 (Invitrogen; Thermo Fisher Scientific, Carlsbad, CA, USA) with 10\% FBS (Invitrogen; Thermo Fisher Scientific) and $0.01 \mathrm{mg} / \mathrm{ml}$ human recombinant insulin (cat no. I3536; Sigma-Aldrich). The cultures were maintained at $37^{\circ} \mathrm{C}$ in a humidified incubator containing 5\% (v/v) $\mathrm{CO}_{2}$ in air. Cells were seeded at a density of $1 \times 10^{6}$ cells $/ \mathrm{ml}$ in 6 -well plates.

MTT assay. MCF-7 cells (5x103/well) were plated in 96-well plates and cultured overnight. MTT solution (volume, $20 \mu \mathrm{l}$; concentration, $5 \mathrm{mg} / \mathrm{ml}$; Sigma-Aldrich) was added to each well and then incubated for another $4 \mathrm{~h}$. The supernatant was removed and DMSO $(150 \mu \mathrm{l})$ was added for test preparation. Absorbance was measured at $490 \mathrm{~nm}$. Data were obtained from triplicate wells per condition.

Flow cytometry for cell cycle and apoptosis analysis. Cells in 6 -well plates were collected using $0.25 \%$ trypsase $24 \mathrm{~h}$ after chrysophanol treatment. Cells were washed twice with PBS butter and then resuspended in $250 \mu 1$ of binding buffer. Cells were fixed in $1 \%$ paraformaldehyde for $24 \mathrm{~h}$ and then stained with $5 \mathrm{mg} / \mathrm{ml}$ propidium iodide for cell cycle analysis. Cells were stained with propidium iodide and Annexin V/FITC for cell apoptosis analysis. Stained cells were analyzed by FACS Calibur flow cytometer (BD Biosciences, San Diego, CA, USA) after incubation in the dark for $15 \mathrm{~min}$.

Western blot analysis. Total protein of MCF-7 cells was extracted using lysis buffer (Pierce Biotechnology, Inc., Rockford, IL, USA) and Bradford method was used to quantify the protein. When SDS-PAGE assay was performed, $30 \mu \mathrm{g}$ of the protein was separated and then transferred to polyvinylidene fluoride membranes (Millipore Corp., Billerica, MA, USA). For primary antibody incubation, cleaved caspase 3 , caspase 3, cleaved PARP, PARP, p-p65, p65, p-IкB, IкB, Bcl-2 (1:1,000; Cell Signaling Technology, Inc., Danvers, MA, USA), and GAPDH (1:2,000; Cell Signaling Technology, Inc.) were incubated overnight at $4^{\circ} \mathrm{C}$. For secondary antibody incubation, peroxidase-coupled anti-mouse/rabbit $\operatorname{IgG}(1: 1,000$; Cell Signaling Technology, Inc.) was incubated at $37^{\circ} \mathrm{C}$ for $2 \mathrm{~h}$. Sample protein was visualized using ECL (Pierce Biotechnology, Inc.) and detected using a DNR BioImaging System (DNR Bio-Imaging Systems, Ltd., Jerusalem, Israel). Relative protein levels were quantified using ImageJ software.

Realtime quantitative PCR. Total RNA was isolated from MCF-7 cells using TRIzol reagent (Thermo Fisher Scientific) following the manufacturer's instructions. Then, reverse transcription of total RNA into cDNA was performed using the Reverse Transcription System (A3500; Promega Corp., Madison, WI, USA) and PrimerScript RT Master Mix kit (Takara Bio, Dalian, China). Briefly, a total $20 \mu$ l of reverse-transcription reaction solution was prepared containing $4 \mu \mathrm{l}$ of $5 \mathrm{X}$ RT Master Mix and 800 ng RNA and the mixture was reacted at $85^{\circ} \mathrm{C}$ for $2 \mathrm{~min}$ and $37^{\circ} \mathrm{C}$ for $30 \mathrm{~min}$. PCR was performed using 7500 Realtime PCR System (Applied Biosystems Life Technologies, Foster City, CA, USA) and SYBR-Green master mix kit (Applied Biosystems Life Technologies). The relative expression of target genes were calculated as $\Delta \mathrm{Cq}=\mathrm{Cq}$ gene-Cq reference, and the fold change of target gene expression was calculated by the $2^{-\Delta \Delta C q}$ method. GAPDH was used as the reference gene. Experiments were repeated in triplicate. Primer sequences were listed as follows: Cyclin D1 forward TGGAGGTCTGCGAGGAACA, cyclin D1 reverse TTCATC TTAGAGGCCACGAACAT; cyclin E forward AGCCAGCCT TGGGACAATAAT, cyclin E reverse GAGCCTCTGGAT GGTGCAAT; p27 forward CTGCAACCGACGATTCTT CTACT, p27 reverse CTTCTGAGGCCAGGCTTCTT; GAP DH forward AAGATCATCAGCAATGCCTCCT, GAPDH reverse TGGTCATGAGTCCTTCCACGAT.

Statistical analysis. Statistical analyses were performed using SPSS version 16 for Windows. The Student's t-test was used to compare differences between control and treatment groups. $\mathrm{P}<0.05$ was considered to indicate a statistically significant difference.

\section{Results}

Chrysophanol inhibits breast cancer cell proliferation and cell cycle progression. MCF-7 and MDA-MB-231 cells were employed to explore effect of chrysophanol on breast cancer. Cells were treated with chrysophanol at the concentrations of $0,5,10,20 \mu \mathrm{M}$. MTT assay and cell cycle analysis were performed. As shown in Fig. 1A, proliferation rates of MCF-7 and MDA-MB-231 cells were decreased significantly when treated with chrysophanol in a concentration-dependent manner after $48 \mathrm{~h}$ treatment. Cycle analysis results showed that G1 percentage increased while $S$ percentage decreased after chrysophanol treatment $(24 \mathrm{~h})$ in a concentration-dependent manner (Fig. 1B), indicating chrysophanol could arrest breast cancer cells at G1-S cell cycle checkpoint.

Chrysophanol regulates cell cycle related proteins. Western blot analysis and real-time quantitative PCR were used to determine the change of cycle related genes (Fig. 2). Western blot analysis results showed that chrysophanol exposure dramatically inhibited expression of cyclin D1, cyclin E while upregulated p21 levels in a concentration dependent manner in both MCF-7 and MDA-MB-231 cell lines $(0,5,10,20 \mu \mathrm{M}$, 24 h) (Fig. 2A). In accordance with western blot analysis results, PCR results showed cyclin D1 and cyclin E mRNA levels decreased when treated with chrysophanol. The mRNA expression of p27 was upregulated in both cell lines in a dose dependent manner (0, 5, 10, $20 \mu \mathrm{M}, 24 \mathrm{~h})$ (Fig. 2B).

Chrysophanol regulates cell apoptosis and related proteins. To explore effect of chrysophanol on cell apoptosis, MCF-7 and MDA-MB-231 cells were treated with chrysophanol $(20 \mathrm{nM}, 24 \mathrm{~h})$ and stained with Annexin V/PI. As shown in Fig. 3 A\&B, percentage of apoptotic cells was increased significantly when treated with chrysophanol in both cell lines. In order to explore the role of chrysophanol on chemosensitivity, we adopted $5 \mathrm{nM}$ paclitaxel (PTX) to treat MCF-7 
A

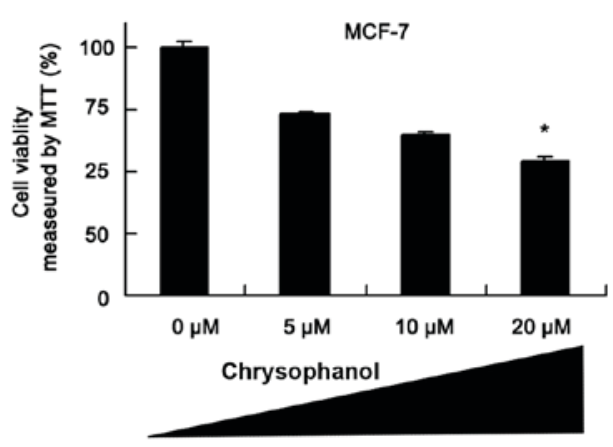

B
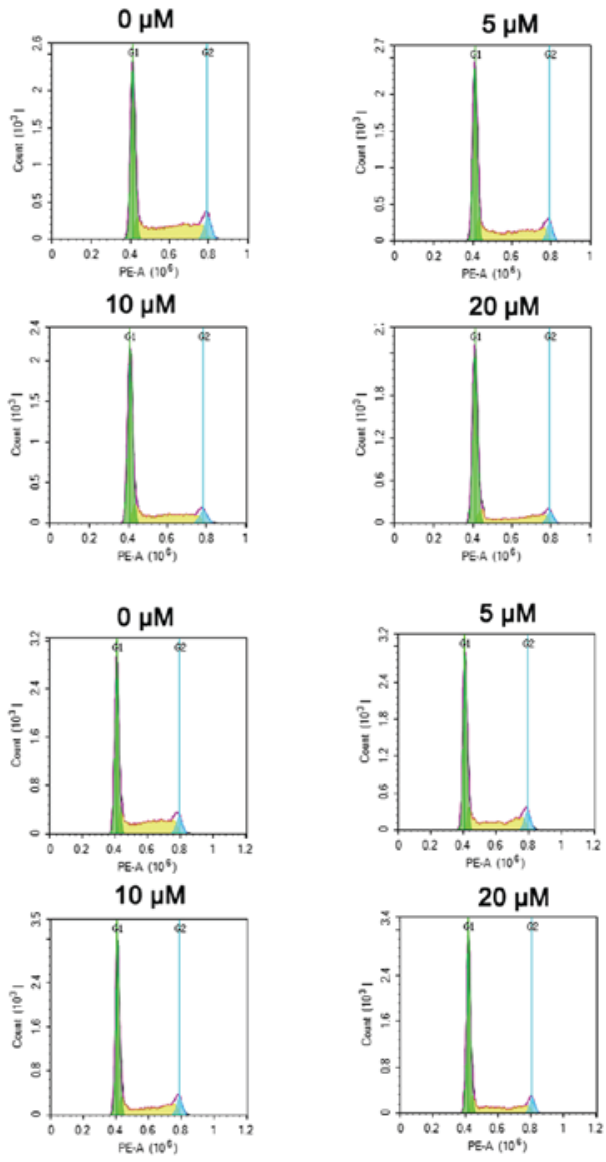

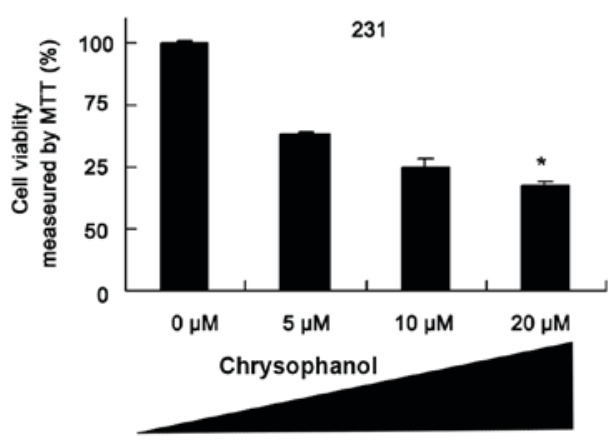

MCF-7

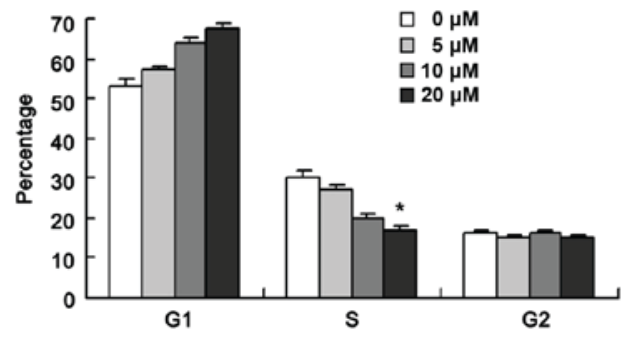

231

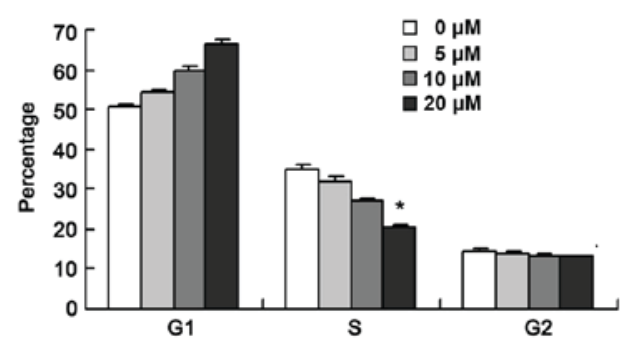

Figure 1. Chrysophanol inhibits breast cancer cell proliferation and cell cycle progression. (A) MTT assay showed that proliferation rates of MCF-7 and MDA-MB-231 cells were decreased significantly when treated with chrysophanol in a concentration-dependent manner after $48 \mathrm{~h}$ treatment $(0,5,10,20 \mu \mathrm{M})$. (B) Cycle analysis results showed that G1 percentage increased while S percentage decreased after chrysophanol treatment (24 h) in a concentration-dependent manner $(0,5,10,20 \mu \mathrm{M}) .{ }^{*} \mathrm{P}<0.05$ compared with control.

and MDA-MB-231 cell lines for $12 \mathrm{~h}$ and examined apoptosis rate after chrysophanol ( $20 \mathrm{nM}, 24 \mathrm{~h})$ treatment. As shown in Fig. 3A and B, chrysophanol significantly increased apoptosis rate in paclitaxel treated breast cancer cells.

Next, expression of apoptosis related protein was examined using western blot analysis and the results showed that chrysophanol treatment upregulated cleaved caspase 3 and cleaved PARP levels in both cell line (Fig. 4). In cells treated with paclitaxel (5 nM, $12 \mathrm{~h}$ ), chrysophanol also significantly upregulated caspase 3 and PARP cleavage in both cell lines (Fig. 5).
Chrysophanol regulates chemosensitivity through $N F-\kappa B$ signaling pathway. To explore the potential mechanism of chrysophanol in MCF-7 and MDA-MB-231 cell lines, we examined several signaling pathways which is related to cancer cell proliferation and chemoresistance. Western blot analysis showed that expression of Bcl-2, p-IкB, p-p65 expression were significantly decreased after treatment with chrysophanol (Fig. 4).

The above results demonstrated that $N F-\kappa B$ activity was suppressed after chrysophanol treatment. Bcl-2 was reported as a downstream target of $\mathrm{NF}-\kappa \mathrm{B}$ signaling, which 
A
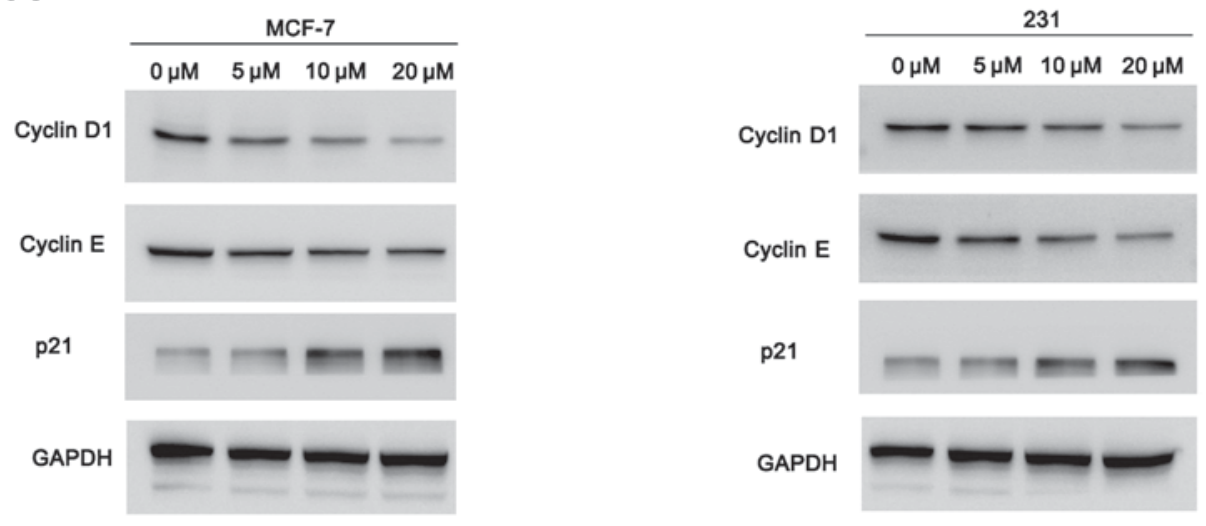

B
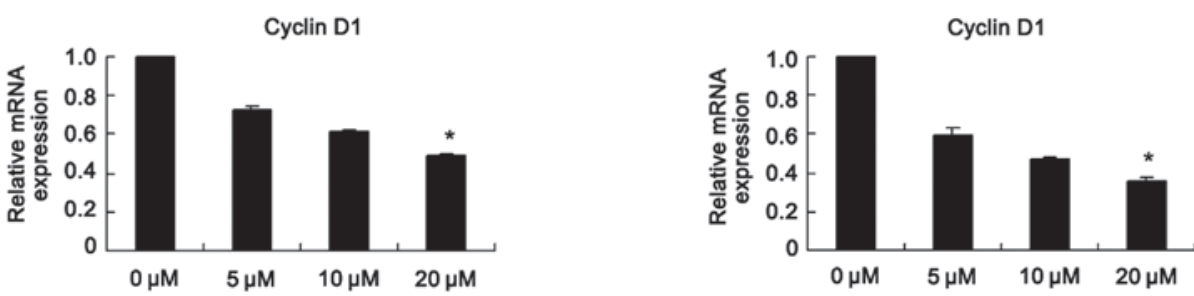

Cyclin E

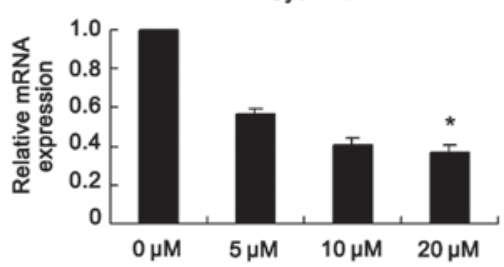

Cyclin E
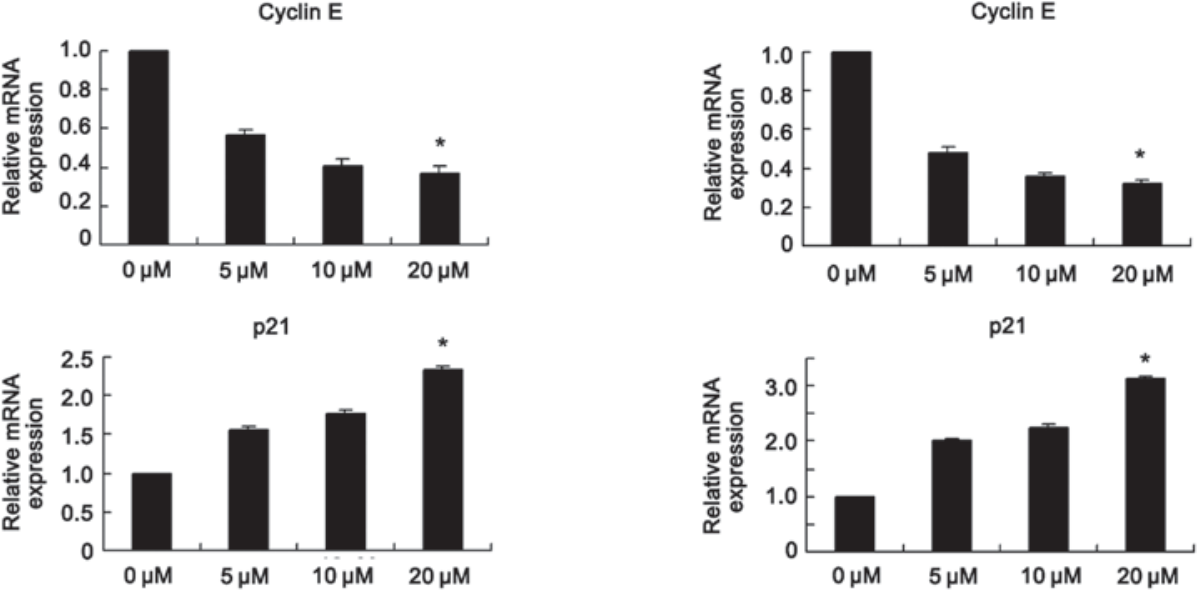

p21

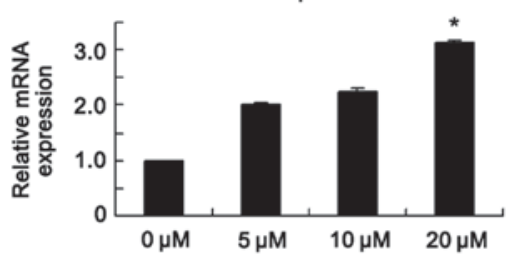

Figure 2. Chrysophanol regulates cell cycle related proteins. (A) Western blot analysis results showed that chrysophanol exposure dramatically inhibited expression of cyclin D1, cyclin E while upregulated p21 levels in a concentration dependent manner in both MCF-7 and MDA-MB-231 cell lines. (B) PCR results showed cyclin D1 and cyclin E mRNA levels decreased when treated with chrysophanol. The mRNA expression of p27 was upregulated in both cell lines in a dose dependent manner. " $\mathrm{P}<0.05$ compared with control.

serves as a potent inhibitor of apoptosis and an indicator of chemoresistance. To confirm if chrysophanol mediated cell behavior was dependent on $\mathrm{NF}-\kappa \mathrm{B}$ signaling pathway, cancer cells were treated with $\mathrm{NF}-\kappa \mathrm{B}$ inhibitor $(10 \mu \mathrm{M})$. Apoptosis analysis was performed and the results showed that difference of PTX induced apoptosis rate between control+ PDTC and chrysophanol+PDTC groups was not as significant as that between control and chrysophanol groups (Fig. 6). As shown in Fig. 7, PDTC blocked NF-кB signaling by reducing $\mathrm{p}-\mathrm{p} 65$ and $\mathrm{p}-\mathrm{I} \kappa \mathrm{B}$ expression. Apoptosis analysis was performed and the results showed that difference of PTX induced apoptosis rate between control+ PDTC and chrysophanol+PDTC groups was not as significant as that between control and chrysophanol groups (Fig. 6 A\&B). In addition, in PDTC treated cells, the role of chrysophanol on Bcl-2 reduction was not significant, suggesting chrysophanol induced chemosensitivity through inhibition of $\mathrm{NF}-\kappa \mathrm{B} / \mathrm{Bcl}-2$ signaling (Fig. 7).

\section{Discussion}

In this study, we used breast cancer cell lines MCF-7 and MDA-MB-231 to examine the anti-tumor effect of chrysophanol. MCF-7 is Luminal A subtype cell with positive ER, PR status and negative HER2 status. MDA-MB-231 cell line is a Basal subtype with negative ER, PR and HER2 status (Triple negative). We chose these 2 cell lines because they represent the most common subtype (Luminal A) and the chemotherapy resistant subtype (Triple negative). As shown in MTT assay, chrysophanol inhibited the proliferation of MCF-7 and MDA-MB-231 cells in a dose-dependent manner. In addition, cell cycle progression was arrested at G1-S point 
A
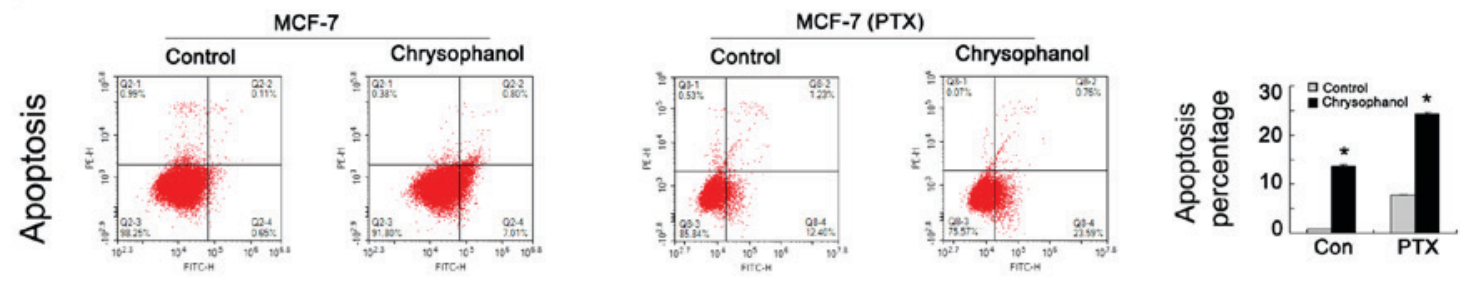

B
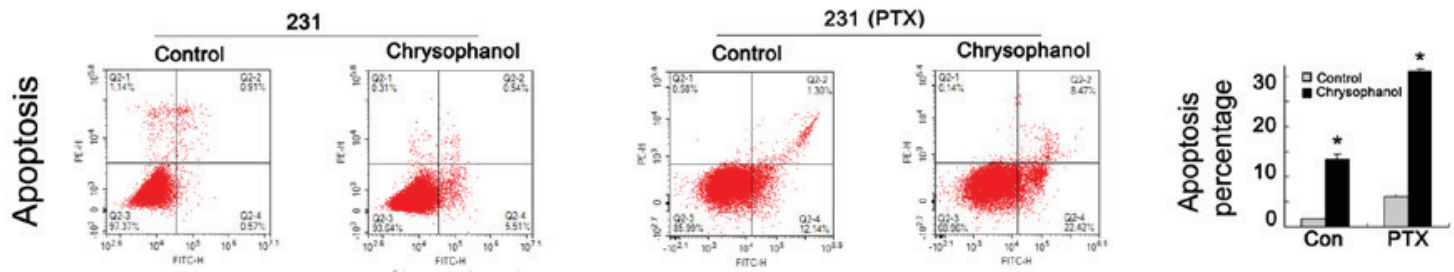

Figure 3. Chrysophanol regulates breast cancer cell apoptosis. (A) Percentage of apoptotic MCF-7 cells was increased significantly when treated with chrysophanol. chrysophanol (20 nM, $24 \mathrm{~h}$ ) also enhanced paclitaxel induced apoptosis in MCF-7 cells. (B) Chrysophanol induced MDA-MB-231 cell apoptosis. chrysophanol $(20 \mathrm{nM}, 24 \mathrm{~h})$ also enhanced paclitaxel induced apoptosis in MDA-MB-231 cells. " $\mathrm{P}<0.05$ compared with control.

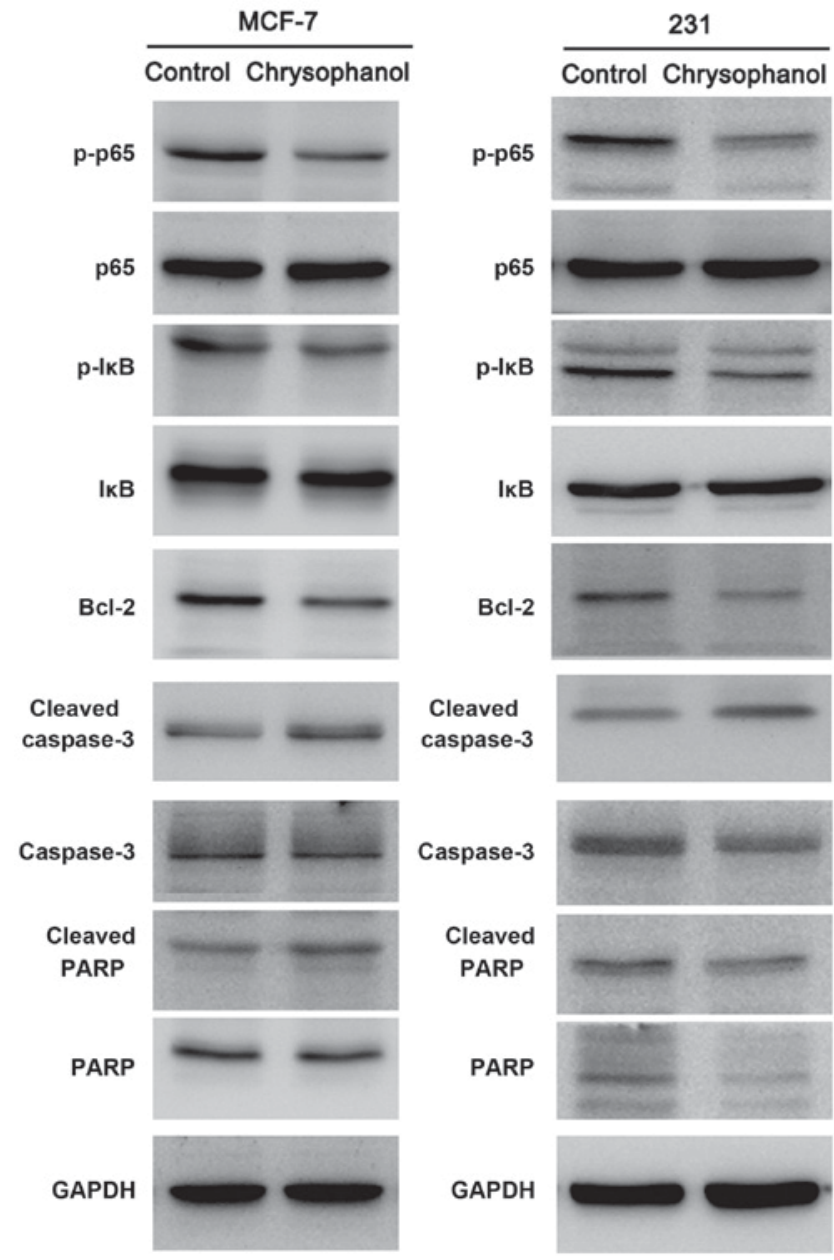

Figure 4. Chrysophanol regulates cell apoptosis and NF-кB related proteins. Chrysophanol treatment upregualted cleaved caspase 3, cleaved PARP levels and downregulated Bcl-2, p-IкB, p-p65 expression in MCF-7 and MDA-MB-231 cell lines.

with downregulation of cyclin family proteins such as cyclin $\mathrm{D} 1$ and cyclin $\mathrm{E}$. When checking signaling pathways involved in chrysophanol mediated effects, we found that chrysophanol

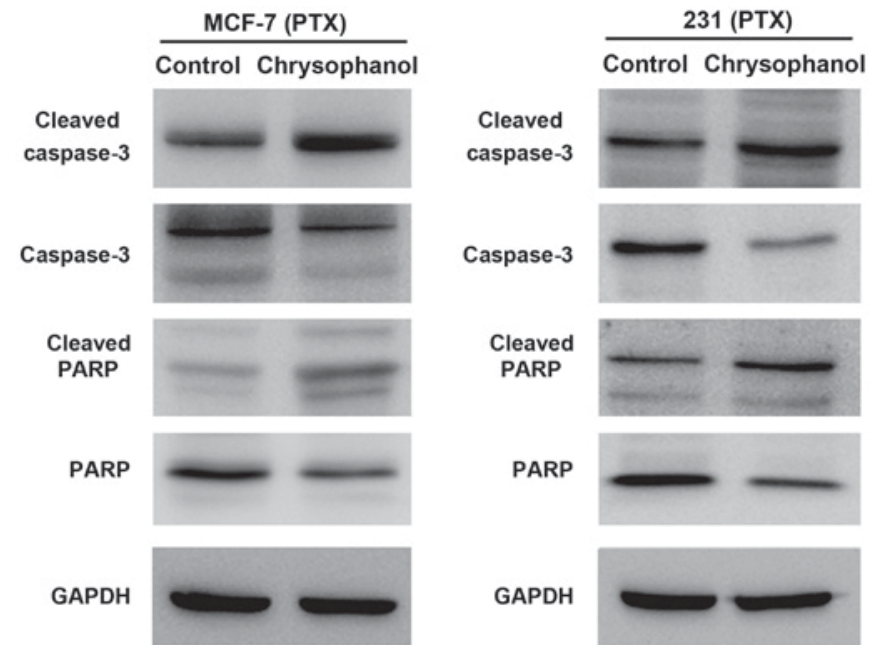

Figure 5. Chrysophanol regulates cell apoptosis related proteins after paclitaxel treatment. In MCF-7 and MDA-MB-231 cells treated with paclitaxel, chrysophanol significantly upregulated cleaved caspase 3 and cleaved PARP while downregulated total caspase 3 and PARP expression.

facilitated PTX induced apoptosis and downregulated Bcl-2. Interestingly, we found that chrysophanol inactivated ІкB and $\mathrm{p} 65$ phosphorylation, which are pivotal tyrosine kinases of NF- $\kappa B$ (18). To confirm the involvement of NF- $\kappa B$ in the anti-cancer effect of chrysophanol, we used NF- $\kappa \mathrm{B}$ inhibitor PDTC. In PDTC treated cells, the effect of chrysophanol on Bcl-2 was not significant compared with normal MCF-7 and MDA-MB-231 cells, suggesting chrysophanol exert its effect through its inhibition of NF- $\kappa$ B activity.

First, we demonstrated that chrysophanol reduced breast cancer cell growth, cell cycle and related proteins in a dose dependent manner. Further study suggested chrysophanol could inhibit NF- $\kappa \mathrm{B}$ activity. NF- $\kappa \mathrm{B}$ activation has been found in many human cancers, which plays important roles in cancer proliferation, invasion and metastasis and associates with poor survival rate (19-21). cyclin D1 and cyclin E play pivotal roles in cell growth of many malignant cancers $(22,23)$. NF- $\mathrm{kB}$ 
A
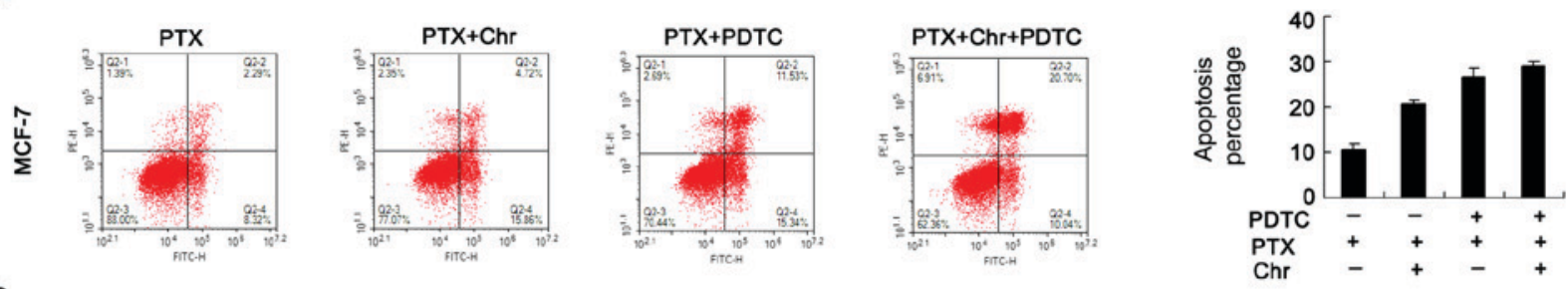

B
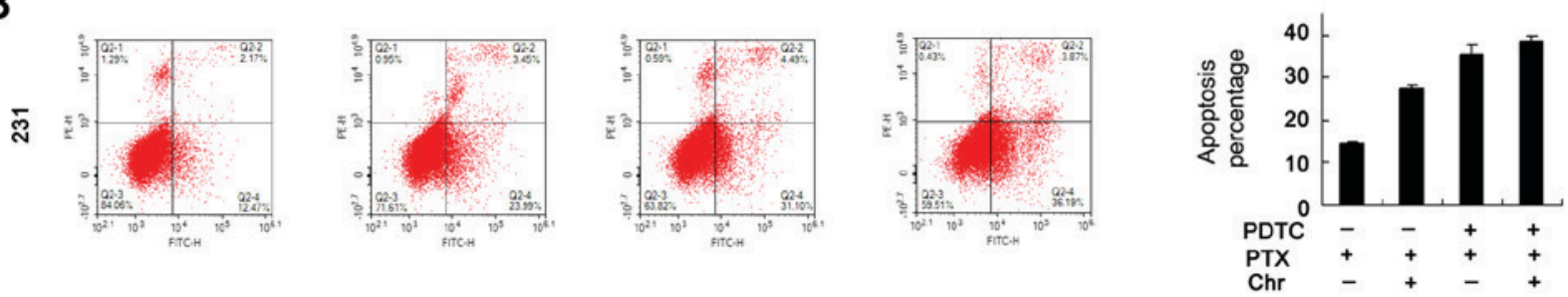

Figure 6. Blockage of NF- $\mathrm{BB}$ abolishes the effect of chrysophanol on apoptosis. (A) In MCF-7 cells treated with paclitaxel (PTX), chrysophanol upregulated the rate of apoptosis. In MCF-7 cells treated with paclitaxel (PTX) and NF- $\mathrm{KB}$ inhibitor PDTC, chrysophanol failed to upregulated apoptosis. (B) In MDA-MB-231 cells treated with paclitaxel (PTX), chrysophanol upregulated the rate of apoptosis. In MDA-MB-231 cells treated with paclitaxel (PTX) and $\mathrm{NF}-\kappa \mathrm{B}$ inhibitor PDTC, chrysophanol failed to upregulated apoptosis. ${ }^{*} \mathrm{P}<0.05$ compared with control.

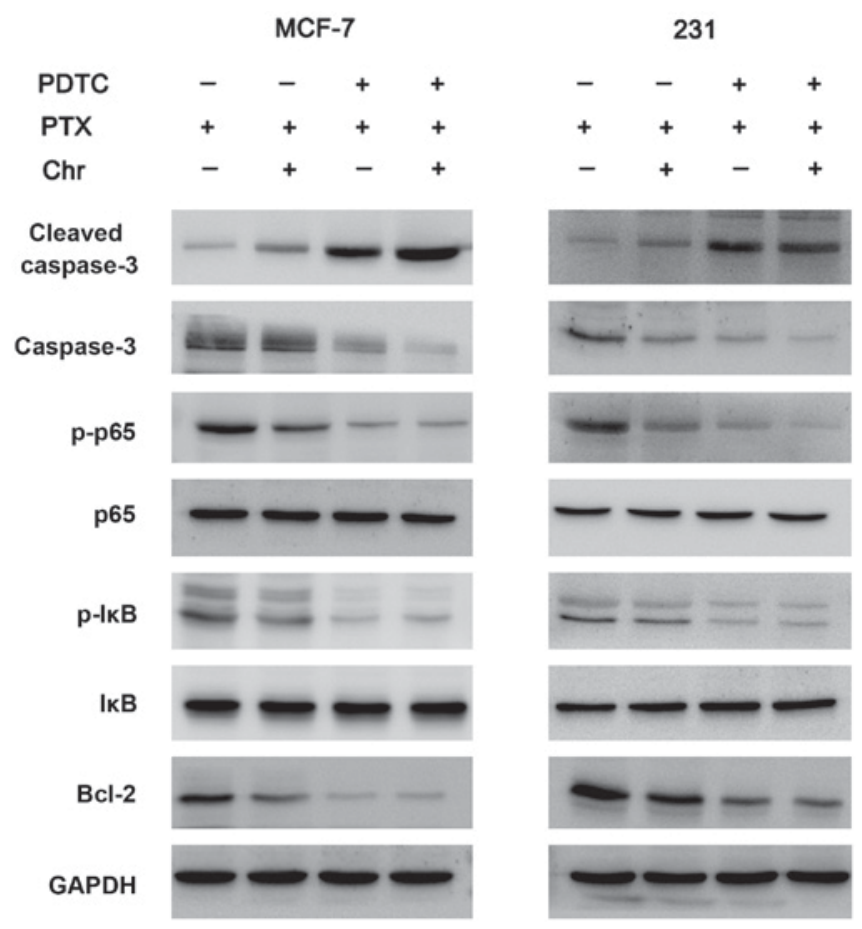

Figure 7. Chrysophanol regulates chemosensitivity through $\mathrm{NF}-\kappa \mathrm{B}$ signaling pathway. PDTC treatment significantly reduced $\mathrm{p}-\mathrm{p} 65$ and $\mathrm{p}-\mathrm{I} \kappa \mathrm{B}$ expression in MCF-7 and MDA-MB-231 cells. In cells without PDTC treatment, chrysophanol significantly reduced Bcl-2 and induced cleaved caspase 3. In PDTC treated cells, the role of chrysophanol on cleaved caspase 3 and Bcl-2 was not significant.

could upregulate its downstream molecule cyclin D1 through phosphorylation of p65 and $\mathrm{I} \kappa \mathrm{B}$, which induced $\mathrm{NF}-\kappa \mathrm{B}$ p 65 nuclear localization and subsequent transcriptional activation of cyclin related proteins (24). Our result was in accordance with these report, suggesting chrysophanol inhibits cancer cell growth through modulation of NF- $\mathrm{B}$ /cyclin signaling.

In addition to the role of chrysophanol on $N F-\kappa B$ related cancer proliferation, we showed that chrysophanol upregulates apoptosis, which is in parallel with downregulation of Bcl-2 protein and cleavage of caspase $3 \&$ PARP. Furthermore, chrysophanol pretreatment enhanced the apoptosis inducing effect of paclitaxel in breast cancer cell lines, suggesting combined treatment would significant enhance the biological effect of PTX. In breast cancer cells, NF- $\mathrm{B}$ signaling activates Bcl-2 which plays a central role in cancer cell survival and chemoresistance. Bcl-2 is overexpressed in breast cancers and serves as an indicator of chemotherapy response. Many studies demonstrated that targeting Bcl-2 inhibits tumor growth and reduces the development of chemoresistance $(25,26)$. Mitochondrial membrane permeability is regulated by the Bcl-2 family of proteins. Compromised mitochondrial membrane integrity leads to downregulated mitochondrial potential. Thus NF- $\kappa \mathrm{B}$ signaling plays an important role during regulation of mitochondrial potential in cancer cells $(27,28)$. These Bcl-2 family anti-apoptotic proteins selectively bind to Bax and block its oligomerization. Bax can then insert into the mitochondrial membrane, compromising its integrity and releasing cytochrome c, which leads to activation of caspase 3 and apoptosis. PARP could be cleaved by caspase 3 in vitro, which is involved in DNA repair in response to environmental stress and serves as a marker of cells undergoing apoptosis $(29,30)$. Thus we postulate that chrysophanol inhibits $\mathrm{NF}-\kappa \mathrm{B} / \mathrm{Bcl}-2$ signaling, which in turn leads to caspase 3/PARP cleavage.

To further validate the relationship between chrysophanol, apoptosis and $\mathrm{NF}-\kappa \mathrm{B} / \mathrm{Bcl}-2$ signaling. NF- $\kappa \mathrm{B}$ inhibitor PDTC was adopted. In PDTC treated cells, the promoting effect of chrysophanol on PTX induced apoptosis was not significant. The change of Bcl-2 induced by chrysophanol was also diminished. Together, our results revealed that chrysophanol targets $\mathrm{NF}-\kappa \mathrm{B} / \mathrm{Bcl}-2$ to suppress breast cancer cell proliferation and chemoresistance, suggesting chrysophanol could be used as a chemotherapeutic agent towards breast cancer cells.

In conclusion, our study demonstrated that chrysophanol inhibits malignant growth and cell cycle of breast cancer cells by inhibiting phosphorylation of $\mathrm{NF}-\kappa \mathrm{B}$ and its downstream $\mathrm{NF}-\kappa \mathrm{B} /$ cyclin D1 pathways. Chrysophanol also inhibits 
NF-kB/Bcl-2 pathway, which facilitates PTX induced apoptosis. Chrysophanol may serve as a novel therapeutic drug for human breast cancer.

\section{Acknowledgements}

The present study was supported by a grant from the National Nature Science Foundation of Liaoning Province (grant no. 201602306).

\section{References}

1. Golshan M, Cirrincione CT, Sikov WM, Carey LA, Berry DA Overmoyer B, Henry NL, Somlo G, Port E, Burstein HJ, et al: Impact of neoadjuvant therapy on eligibility for and frequency of breast conservation in stage II-III HER2-positive breast cancer: Surgical results of CALGB 40601 (Alliance). Breast Cancer Res Treat 160: 297-304, 2016

2. Tsuyuki S, Senda N, Kanng Y, Yamaguchi A, Yoshibayashi H, Kikawa Y, Katakami N, Kato H, Hashimoto T, Okuno T, et al: Evaluation of the effect of compression therapy using surgical gloves on nanoparticle albumin-bound paclitaxel-induced peripheral neuropathy: A phase II multicenter study by the kamigata breast cancer study group. Breast Cancer Res Treat 160: 61-67, 2016.

3. Ni CH, Yu CS, Lu HF, Yang JS, Huang HY, Chen PY, Wu SH, Ip SW, Chiang SY, Lin JG and Chung JG: Chrysophanol-induced cell death (necrosis) in human lung cancer A549 cells is mediated through increasing reactive oxygen species and decreasing the level of mitochondrial membrane potential. Environ Toxicol 29: 740-749, 2014.

4. Ni CH, Chen PY, Lu HF, Yang JS, Huang HY, Wu SH, Ip SW, Wu CT, Chiang SY, Lin JG, et al: Chrysophanol-induced necrotic-like cell death through an impaired mitochondrial ATP synthesis in Hep3B human liver cancer cells. Arch Pharm Res 35: 887-895, 2012.

5. Lu CC, Yang JS, Huang AC, Hsia TC, Chou ST, Kuo CL, Lu HF, Lee TH, Wood WG and Chung JG: Chrysophanol induces necrosis through the production of ROS and alteration of ATP levels in J5 human liver cancer cells. Mol Nutr Food Res 54: 967-976, 2010.

6. Zhao L, Zhao AG, Zhao G, Xu Y, Zhu XH, Cao ND, Zheng J, Yang JK and Xu JH: Survival benefit of traditional chinese herbal medicine (a herbal formula for invigorating spleen) in gastric cancer patients with peritoneal metastasis. Evid Based Complement Alternat Med 2014: 625493, 2014.

7. Hun Lee J, Shu L, Fuentes F, Su ZY and Tony Kong AN: Cancer chemoprevention by traditional chinese herbal medicine and dietary phytochemicals: Targeting nrf2-mediated oxidative stress/anti-inflammatory responses, epigenetics, and cancer stem cells. J Tradit Complement Med 3: 69-79, 2013.

8. Xu Y, Zhao AG, Li ZY, Zhao G, Cai Y, Zhu XH, Cao ND, Yang JK, Zheng J, Gu Y, et al: Survival benefit of traditional chinese herbal medicine (a herbal formula for invigorating spleen) for patients with advanced gastric cancer. Integr Cancer Ther 12: 414-422, 2013.

9. Lu K, Zhang C, Wu W, Zhou M, Tang Y and Peng Y: Rhubarb extract has a protective role against radiation-induced brain injury and neuronal cell apoptosis. Mol Med Rep 12: 2689-2694, 2015.

10. Hong JY, Chung HJ, Bae SY, Trung TN, Bae K and Lee SK: Induction of cell cycle arrest and apoptosis by physcion, an anthraquinone isolated from rhubarb (rhizomes of rheum tanguticum), in MDA-MB-231 human breast cancer cells. J Cancer Prev 19: 273-278, 2014.

11. Liu H, Xu H, Zhang C, Gao M, Gao X, Ma C, Lv L, Gao D, Deng S, Wang $\mathrm{C}$ and Tian Y: Emodin-loaded PLGA-TPGS nanoparticles combined with heparin sodium-loaded PLGA-TPGS nanoparticles to enhance chemotherapeutic efficacy against liver cancer. Pharm Res 33: 2828-2843, 2016.

12. Ma JW, Hung CM, Lin YC, Ho CT, Kao JY and Way TD Aloe-emodin inhibits HER-2 expression through the downregulation of Y-box binding protein-1 in HER-2-overexpressing human breast cancer cells. Oncotarget 7: 58915-58930, 2016.
13. Pan FP, Zhou HK, Bu HQ, Chen ZQ, Zhang H, Xu LP, Tang J, Yu QJ, Chu YQ, Pan J, et al: Emodin enhances the demethylation by 5-Aza-CdR of pancreatic cancer cell tumor-suppressor genes P16, RASSF1A and ppENK. Oncol Rep 35: 1941-1949, 2016.

14. Li KT, Duan QQ, Chen Q, He JW, Tian S, Lin HD, Gao Q and Bai DQ: The effect of aloe emodin-encapsulated nanoliposome-mediated r-caspase-3 gene transfection and photodynamic therapy on human gastric cancer cells. Cancer Med 5: 361-369, 2016.

15. Liu H, Gao M, Xu H, Guan X, Lv L, Deng S, Zhang C and Tian Y: A promising emodin-loaded poly (lactic-co-glycolic acid)-d- $\alpha$-tocopheryl polyethylene glycol 1000 succinate nanoparticles for liver cancer therapy. Pharm Res 33: 217-236, 2016.

16. Kim SJ, Kim MC, Lee BJ, Park DH, Hong SH and Um JY: Anti-Inflammatory activity of chrysophanol through the suppression of NF-kappaB/caspase-1 activation in vitro and in vivo. Molecules 15: 6436-6451, 2010.

17. Lim W, Yang C, Bazer FW and Song G: Chrysophanol induces apoptosis of choriocarcinoma through regulation of ROS and the AKT and ERK1/2 pathways. J Cell Physiol 232: 331-339, 2017.

18. Liu C, Wu XL, Wu XY, Zhang ZH and Liu XH: Effect of NF-кB p65 antisense oligodeoxynucleotide on transdifferentiation of normal human lens epithelial cells induced by transforming growth factor- $\beta 2$. Int J Ophthalmol 9: 29-32, 2016.

19. Hsieh SC, Hsieh WJ, Chiang AN, Su NW, Yeh YT and Liao YC: The methanol-ethyl acetate partitioned fraction from Chinese olive fruits inhibits cancer cell proliferation and tumor growth by promoting apoptosis through the suppression of the NF- $\kappa \mathrm{B}$ signaling pathway. Food Funct 7: 4797-4803, 2016.

20. Meng Y, Hu J, Chen Y, Yu T and Hu L: Silencing MARCH1 suppresses proliferation, migration and invasion of ovarian cancer SKOV3 cells via downregulation of $\mathrm{NF}-\kappa \mathrm{B}$ and $\mathrm{Wnt} / \beta$-catenin pathways. Oncol Rep 36: 2463-2470, 2016.

21. Thoompumkal IJ, Rehna K, Anbarasu K and Mahalingam S: Leucine zipper down-regulated in cancer-1 (LDOC1) interacts with Guanine nucleotide binding protein-like 3-like (GNL3L) to modulate nuclear factor-kappa $\mathrm{B}(\mathrm{NF}-\mathrm{\kappa} \mathrm{B})$ signaling during cell proliferation. Cell Cycle 15: 3251-3267, 2016.

22. Park GH, Song HM and Jeong JB: The coffee diterpene kahweol suppresses the cell proliferation by inducing cyclin D1 proteasomal degradation via ERK1/2, JNK and GKS3 $\beta$-dependent threonine-286 phosphorylation in human colorectal cancer cells. Food Chem Toxicol 95: 142-148, 2016

23. Yuan C, Zhu X, Han Y, Song C, Liu C, Lu S, Zhang M, Yu F, Peng Z and Zhou C: Elevated HOXA1 expression correlates with accelerated tumor cell proliferation and poor prognosis in gastric cancer partly via cyclin D1. J Exp Clin Cancer Res 35: 15, 2016.

24. El-Kady A, Sun Y, Li YX and Liao DJ: Cyclin D1 inhibits whereas c-Myc enhances the cytotoxicity of cisplatin in mouse pancreatic cancer cells via regulation of several members of the NF- $\kappa \mathrm{B}$ and Bcl-2 families. J Carcinog 10: 24, 2011.

25. Fennell DA: Bcl-2 as a target for overcoming chemoresistance in small-cell lung cancer. Clin Lung Cancer 4: 307-313, 2003.

26. Reed JC: Bcl-2 family proteins: Strategies for overcoming chemoresistance in cancer. Adv Pharmacol 41: 501-532, 1997.

27. Abbaspour Babaei M, Zaman Huri H, Kamalidehghan B, Yeap SK and Ahmadipour F: Apoptotic induction and inhibition of NF- $\mathrm{KB}$ signaling pathway in human prostatic cancer PC 3 cells by natural compound 2,2'-oxybis (4-allyl-1-methoxybenzene), biseugenol B, from Litsea costalis: An in vitro study. Onco Targets Ther 10: 277-294, 2017.

28. Mehmood T, Maryam A, Zhang H, Li Y, Khan M and Ma T: Deoxyelephantopin induces apoptosis in HepG2 cells via oxidative stress, NF- $\mathrm{kB}$ inhibition and mitochondrial dysfunction. Biofactors 43: 63-72, 2017.

29. Um HD: Bcl-2 family proteins as regulators of cancer cell invasion and metastasis: A review focusing on mitochondrial respiration and reactive oxygen species. Oncotarget 7: 5193-5203, 2016.

30. Yang D, Chen MB, Wang LQ, Yang L, Liu CY and Lu PH: Bcl-2 expression predicts sensitivity to chemotherapy in breast cancer: A systematic review and meta-analysis. J Exp Clin Cancer Res 32: 105, 2013.

This work is licensed under a Creative Commons Attribution-NonCommercial-NoDerivatives 4.0 International (CC BY-NC-ND 4.0) License. 